\title{
Benzoksazolon Türevi Şalkon Bileşiklerinin Sentezi ve Biyoaktivitelerinin Araștırılması
}

\author{
Sinan Bilginer ${ }^{1 *} \mathrm{C}$ \\ ${ }^{1}$ Atatürk Üniversitesi Eczacılık Fakültesi Farmasötik Kimya AD, Erzurum
}

Geliş / Received: 08/01/2020, Kabul / Accepted: 18/03/2020

\begin{abstract}
Öz
$\mathrm{Bu}$ çalışmada, genel kimyasal yapısı 6-(3-Aril-2-propen-1-oil)-2(3H)-benzoksazolon olan ve aril kısmı benzen, furan veya tiyofen olarak tasarlanan üç adet bileşik başarıyla sentezlenmiş ve yapılar $1{ }^{1} \mathrm{H} N M R,{ }^{13} \mathrm{C}$ NMR ve HRMS spektrumları ile aydınlatılmıştır. Bileşik 2, 6-[3-(Furan-2-il)-2-propen-1-oil]-2(3H)benzoksazolon, sentezi ile ilk kez bu çalışmada rapor edilmiştir. Sentezlenen bileşiklerin sitotoksik aktiviteleri (bileşik 1 hariç), karbonik anhidraz inhibitör aktiviteleri (1-3) ve asetilkolin esteraz inhibitör aktiviteleri (1-3) ise ilk kez bu çalı̧̧ma ile rapor edilmiştir. Bileşiklerin tümünün $\mathrm{AChE}$ enzim inhibitör aktiviteleri referans bileşikten yüksekken, sitotoksik ve hCA I/II inhibitör aktiviteleri referans bileşiklerden düşüktür. Yalnızca bileşik 2, referans bileşik AZA'ya benzer hCA I inhibisyon göstermiştir. Ayrıca, bileşiklerin aril kısmına fenil halkasının getirilmesinin, tiyofen veya furan halkasına göre, sitotoksik ve AChE enzim inhibitör aktiviteleri açısından daha faydalı bir modifikasyon olduğu bu çalışma ile ortaya konulmuştur. Bundan başka, sentezlenen bileşiklerin yüksek AChE inhibitör aktiviteleri nedeniyle ileriki çalışmalar için uygun öncü bileşikler oldukları görülmüştür.
\end{abstract}

Anahtar Kelimeler: Asetilkolin esteraz, benzoksazolon, karbonik anhidraz, şalkon, sitotoksisite

\section{Synthesis and Bioactivities of Benzoxazolone Derivative Chalcone Compounds}

\begin{abstract}
In this study, three compounds, 6-(3-aryl-2-propen-1-oyl)-2(3H)-benzoxazolones, whose aryl part is designed as benzene, furan or thiophene were synthesized successfully and their chemical structures were confirmed by ${ }^{1} \mathrm{H}$ NMR, ${ }^{13} \mathrm{C}$ NMR, and HRMS spectra. Compound 2, 6-[3-(Furan-2-yl)-2-propen-1-oyl]-2(3H)benzoxazolone, was reported for the first time with its synthesis in this study. Cytotoxic activities (except compound 1), carbonic anhydrase inhibitory activities (1-3) and acetylcholine esterase (AChE) inhibitory activities (1-3) of synthesized compounds were reported for the first time in this study. The AChE enzyme inhibitory activities of all compounds were higher than the reference compound, while the cytotoxicities and hCA I/II inhibitory activities of the compounds were lower than the reference compounds. Only compound 2 showed similar inhibitory activity with reference drug AZA against hCA I. Furthermore, in this study, it was shown that introducing the phenyl ring as the aryl moiety of the compounds was a more useful modification than the thiophene or furan rings in terms of the cytotoxic and AChE enzyme inhibitory activities. On the other hand, all synthesized compounds were found to be as candidate molecules for further studies due to their high AChE inhibitory activities.
\end{abstract}

Keywords: Acetylcholinesterase, benzoxazolone, carbonic anhydrase, chalcone, cytotoxicity

\footnotetext{
*Sorumlu Yazar: sinanbilginer25@yahoo.com
} 


\section{Giriş}

Kanser, kardiyovasküler sistem hastalıklarından sonra dünyada ikinci sirada ölüm nedeni olan bir hastalıktır. Dünya Sağlik Örgütü raporlarına göre kanser nedeniyle 2040 yilına kadar 16.5 milyon insanın öleceği öngörülmektedir (Ferlay et al., 2019). Dolayısıyla dünya genelinde kanser tedavisi üzerine yoğun çalışmalar devam etmektedir. $\mathrm{Bu}$ alandaki yoğun ve maliyetli çalışmalara rağmen kanser hastalarının ancak \%20-25'i tedavi edilebilmektedir (Palaska, 2004). Klinikte kullanılan antikanser ilaçların düşük seçiciliklerine ek olarak saç dökülmesi, kusma, ağrı gibi ciddi yan etkileri mevcuttur. $\mathrm{Bu}$ sebeple toksisitesi düşük, selektivitesi yüksek yeni antikanser ilaçlara ihtiyaç bulunmaktadır.

Yaşlılarda görülen demansın en yaygın şekli olan Alzheimer hastalığı, hafıza, konuşma, insanları tanıma, problem çözme vb. günlük yaşamda rutin olarak gerçekleştirilen pratiklerin ve çeşitli zihinsel işlevlerin zamanla zayıfladığı ve davranış bozukluklarının görülebildiği ilerleyici bir beyin hastalığıdır (Cacabelos, 2008; Di Resta ve Ferrari, 2019; Koca et al., 2016; Yerdelen ve Gul, 2013). Alzheimer, sosyal ve tıbbi bakım açılarından yüksek maliyetler nedeniyle hastalarin, ailelerinin ve de toplumun yaşam tarzı üzerinde olumsuz etkilere sahip bir hastalıktır (Di Resta ve Ferrari, 2019). Alzheimer'in patogenezini anlamada büyük ilerlemeler olmasına rağmen, bu hastalığın henüz kesin bir tedavisi yoktur. Mevcut tedaviler semptomları geçici olarak hafifletmekle sinırlıdır (Yerdelen ve Gul, 2013). Limbik yolağın bellek süreçlerini yöneten kısmındaki nöronların kaybı Alzheimer hastalığının tanısındaki önemli bulgulardan biridir
(Zvěřová, 2019). Alzheimer hastalığında, serebral korteksin nörotransmitter içeriğinin ölçülmesi sonucunda, nöron kaybına paralel olarak birçok nörotransmitterin, en çok da asetilkolinin azaldığı görülmüştür. Yani kolinerjik sistemdeki değişim ile Alzheimer arasında bir ilişki bulunmaktadır. Kolinerjik hipotez olarak açıklanan bu ilişkiye göre, asetilkolin düzeyindeki azalma Alzheimer hastalığ 1 ile ilişkilidir (Cacabelos, 2008; Koca et al., 2016; Zvěřová, 2019). Kolinerjik hipotez Alzheimer hastalarında gözlenen kognitif düşüşün açıklanmasına önemli katkıda bulunmuş, Alzheimer hastalığının tedavi stratejilerinin ve ilaç geliştirme çalışmalarının çoğunun temelini oluşturmuştur. Sonuç olarak, Alzheimer hastalığının tedavisinde, asetilkolin düzeyinin artırılması ve dolayısıyla da asetilkolini yikan asetilkolinesteraz enziminin inhibe edilmesi en sık başvurulan tedavi yaklaşımlarından biridir.

Kolinesterazlar olarak da bilinen asetilkolinesteraz (AChE) ve bütirilkolinesteraz (BChE) serin hidrolaz enzim ailesinin iki önemli üyesidir (Gul et al., 2017; Zhang et al., 2019). AChE, sinapslarda asetilkolinin hidrolizini katalizlemektedir (Gul et al., 2017; Koca et al., 2016). Günümüzde asetilkolinesteraz inhibitörü ilaçlar Alzheimer tedavisinde kullanılmaktadır. Bu ilaçlar hepatotoksisite, bulant1, kusma, diyare gibi yan etkilere sahiptirler (Anand ve Singh, 2013; Loveman et al., 2006; Rivas-Vazquez, 2001). Dolayısıyla yan etkisi azaltılmış, santral ve periferik AChE inhibisyonu yapan yeni AChE inhibitörü bileşiklere ihtiyaç duyulmaktadır.

Karbonik anhidraz (CA), karbondioksitle bikarbonat arasındaki dönüşüm reaksiyonunu katalizleyen bir enzim ailesidir (Supuran ve 
Scozzafava, 2007). Şimdiye kadar genetik olarak sekiz farklı CA ailesi $(\alpha-, \beta-, \gamma-, \delta-, \zeta-$ $\eta-, \theta$ - ve -CAs ) tanımlanmıştır (Supuran, 2008; Thacker et al., 2019). İnsanlarda, farkl1 katalitik aktiviteye sahip 12 farklı aktif $\alpha-\mathrm{CA}$ izoformu vardır (Langella et al., 2019). Bu enzimler vücutta geniş dağılım gösterirler ve asit-baz regülasyonu, biyosentetik reaksiyonlar, elektrolit sekresyonu gibi birçok önemli fizyolojik ve patolojik olayda görev alırlar (Supuran, 2008). Dolayısıyla, insan CA enzimlerinin (hCA) aktivasyonu veya inhibisyonu birçok hastalığın teşhis ve/veya tedavisinde önemli bir stratejidir ve bu aktiviteye sahip ilaçların klinik kullanımları mevcuttur. Antiglokom ilaçlar (hCA I, II, IV, XII), diüretikler (hCA II, IV, XII, XIV) ve antiepileptik ilaçlar (hCA II, IV, XIV, XIV) CA inhibitörü ilaçlara örnek olarak verilebilirler (Alterio et al., 2012; Supuran, 2017, 2018).

Klinikte yaygın olarak kullanılan en önemli kemoterapötik ilaçlar alkilleyici antikanser ajanlardır. Alkilleyici ajanlar içerisinde de $\alpha, \beta$-doymamış ketonlar önemli yer tutmaktadırlar. $\quad \alpha, \beta$-doymamış bileşiklerin hem antikanser özelliklerinin güçlü olmasından hem de yan etkilerinin çok az olmasından dolayı son yıllarda çalışmalar bu grubu içeren bileşikler üzerinde yoğunlaşmıştır. $\alpha, \beta$ - doymamış ketonların nükleik asitlerde bulunan amin ve hidroksil gruplarına karşı ilgisi yok denecek kadar az iken tiyollere karşı ilgisi yani reaktivitesi fazladır. Kanser hücrelerinde ise glutatyon (GSH) oranının artmış olduğu dikkate alındığında bu özellik, selektif sitotoksisite açısından çok değerlidir. Bu bileşikler ile yapılacak olası bir tedavide nükleik asitlerle etkileşimden kaynaklanacak yan etkiler bertaraf edilir (Erciyas, Erkaleli, ve Cosar, 1994; Gul et al., 2009). Ayrıca, bazı $\alpha, \beta$ doymamış bileşiklerin hem AChE'a hem de
BChE'a karşı yüksek inhibisyon gösterdikleri rapor edilmişlerdir (Yerdelen ve Gul, 2013).

Şalkonlar ise 1,3-diaril-2-propenon yapısındaki $\alpha, \beta$-doymamış keton bileşikleridir (Kandepu, 2002). Aril halkasındaki sübstitüsyona bağlı olarak çok geniş biyolojik aktiviteye sahiptirler. Şalkonların antiinflamatuvar (De et al., 1995; Nowakowska, 2007), antimikrobiyal (Baviskar et al., 2009), antifungal (Lahtchev et al., 2008), antioksidan (Miranda et al., 2000), antimalaryal (M Chen et al., 1997), antileishmanyal (M Chen et al., 1993; Rocha et al., 2005), antitümör (Abonia et al., 2012), antikanser (Cunha et al., 2003; Toru et al., 2000), sitotoksik (Bilginer et al., 2013; Gul et al., 2018), asetilkolinesteraz inhibitör (Hasan et al., 2005; Liu et al., 2014) ve karbonik anhidraz inhibitör (Bilginer et al., 2014; Gul et al., 2018; Yamali et al., 2016) etkileri rapor edilmiştir.

Benzoksazolon halkası, kimyasal reaktivitesi ve çok çeşitli biyolojik aktivitelerinden dolayı literatürde "ayrıcalıklı iskelet" olarak tanımlanır (Murty et al., 2011). Benzoksazolon ve türevleri kas gevşetici (Lespagnol et al. 1952; Vigroux ve Bergon, 1995), analjezik (Bonte ve Lesieur, 1974; Mulazim et al., 2017), antiviral (Wang ve $\mathrm{Ng}, \quad 2002)$ antikanser (El-Hady ve Abubshait, 2015; Ivanova et al., 2007), antiinflamatuvar (Gulcan et al., 2003) ve antimikrobiyal (Köksal et al., 2002) etkiler gibi çok çeşitli biyolojik aktivitelere sahiptirler. Literatürde ve ayrıca grubumuza ait çalışmalarda 2(3H)-benzoksazolon taşıyan şalkon yapısındaki bileşiklerin yüksek sitotoksik özellik gösterdikleri rapor edilmiştir (Bilginer et al., 2019; Yordanka et al., 2009; Ivanova et al., 2007; Y. B. Ivanova et al., 2013). Bu bileşiklerin güçlü ve selektif sitotoksisiteleri, bu kimyasal yapıdaki 

bileşiklerin tasarımının önemini
göstermektedir. Ayrıca, grubumuza ait söz konusu çalışmada bu kimyasal yapıdaki bileşiklerin insan karbonik anhidraz inhibe edici etkileri de araştırılmış ve kayda değer aktivite gösterdikleri bulunmuştur (Bilginer et al., 2019).

Bu çalışmada, 6-(3-aril-2-propenoil)-2(3H)benzoksazolon yapısındaki üç adet bileşiğin (1-3) sentezlenmesi amaçlanmıştır. Şalkon yapısında bulunan fenil halkasının, izosterleri olan furan veya tiyofen ile değiştirilmesi planlanmıştır. Ayrıca bu çalışmada, sentezlenen bileşiklerin sitotoksik özellikleri, hCA I ve hCA II izoenzimlerine karşı inhibisyon potansiyelleri ve asetilkolin esteraz enzim inhibisyon potansiyelleri, olas yeni lider bileşikler bulmak amacıyla araştırılmıştır.

\section{Materyal ve Metot}

\subsection{Materyal}

Bileşiklerin Nükleer Manyetik Rezonans (NMR) Spektrumları Bruker AVANCE III $400 \mathrm{MHz}$ (Bruker, Karlsruhe, Germany) marka cihazda kaydedilmiştir. Kimyasal kayma değerleri $(\delta)$ ppm olarak verilmiştir.
Standart olarak ise Tetrametilsilan (TMS) kullanılmıştır. Bileşiklerin kütle spektrumları, hem pozitif hem de negatif iyonizasyon modunda çalş̧an, bir elektrosprey iyonizasyon (ESI) kaynağı ile donatılmış kütle spektrometresi (Shimadzu, Kyoto, Japonya) kullanılarak alınmıştır. Veri analizi için Shimadzu'nun LC-MS Çözümü yazılımı kullanılmıştır. Erime noktaları Elektrotermal 9100 cihazı (IA9100, Bibby Scientific Limited, Staffordshire, UK) kullanılarak belirlenmiştir. Reaksiyonlar, ince tabaka kromatografisi (ITK) yöntemi ile silikajel plaklar (60 HF254, Merck KGaA) kullanılarak izlenmiştir.

\subsection{Bileșik 1-3'ün sentezi}

6-Asetil-2(3H)-benzoksazolon'un sentezi

Dimetilformamit (13 ml, $172 \mathrm{mmol}$ ) üzerine $80 \mathrm{~g} \quad(600 \mathrm{mmol})$ alüminyum klorür karıştırılarak yavaş yavaş ilave edildi. Karışım $45^{\circ} \mathrm{C}^{\prime}$ de 5 dakika karıştırıldı. Daha sonra, $2(3 H)$-benzoksazolon $(8,1 \mathrm{~g}, \quad 60$ $\mathrm{mmol})$ ve asetil klorür $(6,4 \mathrm{ml}, 90 \mathrm{mmol})$ bu karışım üzerine ilave edildi. Ardından sicaklık $80^{\circ} \mathrm{C}$ 'ye ayarlanarak reaksiyon içeriği 3 saat karıştırıldı. Süre sonunda reaksiyon içeriği, içerisinde $\mathrm{HCl}$ bulunan (30<smiles>C=C(C)c1ccc2[nH]c(=O)oc2c1</smiles>

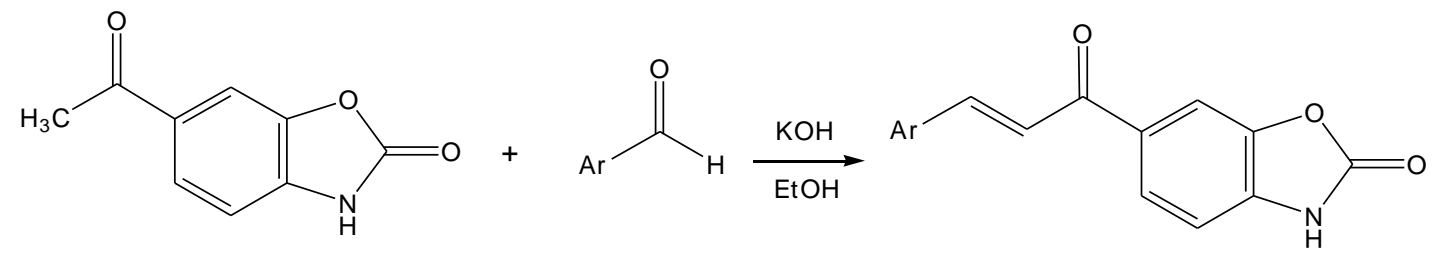

Ar: Fenil (1), 2-Furil (2), 2-Tiyenil (3)

Şema 1. Bileşiklerin sentez şeması 
ml, $37 \%) 200 \mathrm{ml}$ buzlu suya döküldü ve karıştırıldı. Oluşan katı süzüldü, kurutuldu ve etanolden kristallendirildi. \%77 verimle kahverengi kristaller elde edildi (Erimederecesi: 231-234 ${ }^{\circ} \mathrm{C}$ ) (Bilginer et al., 2019; Ivanova et al., 2007).

\section{6-(3-Fenil-2-propen-1-oil)-2(3H)-}

benzoksazolon (1) sentezi (Şema 1)

İlk basamakta sentezlenen 6-Asetil-2(3H)benzoksazolon (5.6 mmol) $5 \mathrm{ml}$ etanolde çözündürülerek üzerine benzaldehit (5.6 mmol) ilave edildi. Reaksiyon karışımının üzerine $5 \mathrm{ml} \mathrm{KOH'in} \mathrm{sulu} \mathrm{çözeltisi} \mathrm{( \% 10)}$ ilave edildi ve 24 saat oda sicaklığında karıştırıldı. Reaksiyonun ilerleyişi İTK ile izlendi. Reaksiyon bittikten sonra reaksiyon içeriği $100 \mathrm{ml}$ buzlu suya döküldü ve karıştırıldı. Karıştırma esnasında reaksiyon içeriği $\mathrm{HCl}(\% 37)$ ile nötralize edildi. Oluşan katı süzüldü, soğuk suyla yıkand1, kurutuldu ve asetonitril:etanol çözücü karışımından kristallendirildi (Bilginer et al., 2019; Ivanova et al., 2007).

6-[3-(Furan-2-il)-2-propen-1-oil]-2(3H)benzoksazolon (2) ve 6-[3-(Tiyofen-2-il)-2propen-1-oil]-2(3H)-benzoksazolon sentezi (Şema 1)

İlk basamakta sentezlenen 6-Asetil-2(3H)benzoksazolon $(5.6 \mathrm{mmol}) 2 \mathrm{ml}$ etanolde çözündürülerek üzerine uygun aldehit (5.6 mmol) ilave edildi. Reaksiyon karışımının üzerine $2 \mathrm{ml} \mathrm{KOH'in} \mathrm{sulu} \mathrm{çözeltisi} \mathrm{( \% 10)}$ ilave edildi. Reaksiyon karışımı mikrodalga cihazında $\left(80{ }^{0} \mathrm{C}^{\prime}\right.$ de 60 Watt) 30 dakika karıştırılarak 1sıtıldı (Bilginer et al., 2019). Reaksiyonun ilerleyişi İTK ile izlendi. Reaksiyon bittikten sonra reaksiyon içeriği $100 \mathrm{ml}$ buzlu suya döküldü ve karıştırıldı. Karıştırma esnasında reaksiyon içeriği $\mathrm{HCl}$ (\%37) ile nötralize edildi. Oluşan katı süzüldü, soğuk suyla yıkandı, kurutuldu ve uygun çözücüden [asetonitril:metanol (2) ve asetonitril:etanol (3)] kristallendirildi.

\subsection{Biyolojik Aktivite Testleri}

Sitotoksisite, karbonik anhidraz inhibisyon ve asetilkolin estreraz inhibisyon testleri daha önceki çalışmalarımızda belirtilen yöntemlerle yapılmıştır (Bilginer et al., 2013; Bilginer et al., 2014; Gul et al., 2017; Gul et al., 2017; Gul et al., 2018; Gul et al., 2017; Yamali et al., 2018; Yamali et al., 2016).

\section{Bulgular}

Sentezlenen bileşiklerin verimleri, erime dereceleri ve $1 \mathrm{H}$ NMR, 13C NMR ve HRMS spektrumlarına ait veriler aşağıda verilmiştir. Bileşiklerin sitotoksisite sonuçları Tablo 1 'de, karbonik anhidraz ve asetilkolin esteraz inhibitör aktiviteleri ise Tablo 2'de verilmiştir.

6-(3-Fenil-2-propen-1-oil)-2(3H)-

benzoksazolon (1)

Verim \%77. E.D: $230-232{ }^{\circ} \mathrm{C} .{ }^{1} \mathrm{H}$ NMR $\left(\mathrm{DMSO}_{\mathrm{d}}\right) \delta(\mathrm{ppm}) 12.03$ (bs, 1H, NH), $8.11(\mathrm{~d}, 1 \mathrm{H}$, arom. H, J=1.2 Hz), 8.07 (dd, $1 \mathrm{H}$, arom. $\left.\mathrm{H}, J_{l}=8.2 \mathrm{~Hz}, J_{2}=1.6 \mathrm{~Hz}\right), 7.99$ $(\mathrm{d}, 1 \mathrm{H}, \mathrm{Ar}-\mathrm{CH}=, J=15.5 \mathrm{~Hz}), 7.89-7.91(\mathrm{~m}$, $2 \mathrm{H}$, arom. H), 7.74 (d, 1H, =CHCO, J=15.5 $\mathrm{Hz}), 7.47$ (d, 1H, arom. H, J=1.2 Hz), 7.45 $(\mathrm{d}, 2 \mathrm{H}$, arom. $\mathrm{H}, J=2.5 \mathrm{~Hz}), 7.24(\mathrm{~d}, 1 \mathrm{H}$, arom. $\mathrm{H}, J=8.2 \mathrm{~Hz}$ ). ${ }^{13} \mathrm{C}$ NMR (DMSO-d 6 ) $\delta$ (ppm) 187.8, 154.9, 144.2, 143.9, 135.5, 135.2, 132.3, 131.0, 129.38, 129.37, 129.36, 126.2, 122.3, 110.0. HRMS (ESI-MS) m/z $[\mathrm{M}+\mathrm{H}]^{+}$hesaplanan 266.0812, ölçülen 266.0803 .

6-[3-(Furan-2-il)-2-propen-1-oil]-2(3H)benzoksazolon (2)

Verim: \%79. E.D: $200-202{ }^{0} \mathrm{C} .{ }^{1} \mathrm{H}$ NMR $\left(\right.$ DMSO-d $\left._{6}\right) \delta(\mathrm{ppm}) 7.98(\mathrm{dd}, 1 \mathrm{H}$, arom. H, 
$\left.J_{l}=8.5 \mathrm{~Hz}, J_{2}=1.6 \mathrm{~Hz}\right), 7.97(\mathrm{~d}, 1 \mathrm{H}$, arom. $\mathrm{H}$, $J=1.6 \mathrm{~Hz}), 7.91$ (d, 1H, arom. H, $J=1.6 \mathrm{~Hz}$ ) 7.57 (s, 2H, $\alpha, \beta$-protonlar) (Kazaz C., 2017), $7.22(\mathrm{~d}, 1 \mathrm{H}, J=8.5 \mathrm{~Hz}), 7.11(\mathrm{~d}, 1 \mathrm{H}$, arom. H, $J=3.4 \mathrm{~Hz}), 6.87(\mathrm{~d}, 1 \mathrm{H}$, arom. $\mathrm{H}, J=3,4 \mathrm{~Hz})$. ${ }^{13} \mathrm{C}$ NMR (DMSO-d $) \delta(\mathrm{ppm}) 187.3,154.9$, $151.7,146.6,143.9,135.4,132.3,130.7$, $126.0,119.0,117.3,113.6,110.0,109.7$. HRMS (ESI-MS) $\mathrm{m} / \mathrm{z}[\mathrm{M}+\mathrm{H}]^{+}$hesaplanan 256.0604, ölçülen 256.0593.

6-[3-(Tiyofen-2-il)-2-propen-1-oil]-2(3H)benzoksazolon (3)

Verim: \%43. E.D: $235-237{ }^{0}$ C. ${ }^{1}$ H-NMR $\left(\mathrm{DMSO}_{\mathrm{d}}\right) \quad \delta$ (ppm) 12.08 (bs, 1H, NH), 8.02-7.98 (m, 2H, arom. H), 7.90 (d, 1H, Ar$\mathrm{CH}=, J=15.2 \mathrm{~Hz}), 7.79(\mathrm{~d}, 1 \mathrm{H}$, arom. $\mathrm{H}, J=$ $5.0 \mathrm{~Hz}), 7.70(\mathrm{~d}, 1 \mathrm{H}$, arom. $\mathrm{H}, J=3.5 \mathrm{~Hz})$, $7.61(\mathrm{~d}, 1 \mathrm{H},=\mathrm{CHCO}, J=15.2 \mathrm{~Hz}), 7.22(\mathrm{~d}$, $1 \mathrm{H}$, arom. $\mathrm{H}, J=8.4 \mathrm{~Hz}), 7.19(\mathrm{dd}, 1 \mathrm{H}$, arom. $\left.\mathrm{H}, J_{1}=3.5, \mathrm{~Hz}, J_{2}=2.6 \mathrm{~Hz}\right) .{ }^{13} \mathrm{C}$ NMR (DMSO-d 6$) \quad \delta(\mathrm{ppm})$ 187.3, 154.9, $143.9,140.2,136.9,135.4,133.2,132.2$, $130.9,129.2,126.1,120.6,110.0,109.8$. HRMS (ESI-MS) $\mathrm{m} / \mathrm{z}[\mathrm{M}+\mathrm{H}]^{+}$hesaplanan 272.0376, ölçülen 272.0368 .

\section{Sonuç ve Tartışma}

\subsection{Kimyasal}

Genel kimyasal yapıs1 6-[3-Aril-2-propen-1oil]-2(3H)-benzoksazolon olan üç adet bileşik Şema 1'de gösterildiği gibi başarıyla sentezlenmiş ve yapıları ${ }^{1} \mathrm{H}$ NMR, ${ }^{13} \mathrm{C}$ NMR ve HRMS spektral analiz yöntemleriyle doğrulanmıştır. Furan türevi bileşik (2) ilk kez grubumuz tarafından sentezlenmiş ve rapor edilmiştir (Kazaz C., 2017).

Şema 1'de gösterildiği üzere, ilk basamakta 2(3H)-benzoksazolon halkası Friedel-Crafts açilasyon reaksiyonu ile 6 numaralı konumdan asetillenmiştir. Halkanın 6 numaralı konuma yönlendirici etkisinden dolayı (Ivanova et al., 2013) 6-asetil-2(3H)benzoksazolon, yüksek verim (\%) ve saflıkta elde edilmiştir. İkinci basamakta ise, elde edilen 6-asetil-2(3H)-benzoksazolon (keton) bileşiği ile uygun aldehit bileşiğinin [benzaldehit (1), furan-2-karbaldehit (2) ve tiyofen-2-karbaldehit (3)] Claisen-Schmidt reaksiyonu sonucunda şalkon bileşikleri elde edilmiştir. Fenil türevi bileşik (1) konvansiyonel şalkon sentezi yöntemiyle sentezlenirken furan (2) ve tiyofen (3) türevi bileşikler mikrodalga yöntemiyle ilk kez ekibimiz tarafından sentezlenmişlerdir. 1 numaralı bileşik \%77 verimle sentezlenirken, 2 ve 3 numaralı bileşikler sırayla $\% 79$ ve $\% 43$ verimle sentezlenmişlerdir.

Bileşiklerin yöntem kısmında sunulan ${ }^{1} \mathrm{H}$ NMR spektrum yorumları, sentezlenen bileşiklerin yapılarının doğrulandığını, ayrıca 1 ve 3 numaralı bileşiklerin $E$ konfigürasyonunda olduklarını ( $J$ sabitleri $15.5 \mathrm{~Hz}$ ve $15.2 \mathrm{~Hz}$ ) göstermektedir ( Ivanova et al., 2013). Bileşiklerde bulunan protonlara ait sinyaller beklenildiği üzere aromatik bölgede (7.0-8.0 ppm) görülmektedir. ${ }^{13} \mathrm{C}$ NMR spektrumları ise bileşiklerin karbon sayılarını doğrulamakta ve karbonil gruplarına ait pikler beklenildiği üzere 187 ppm civarında görülmektedirler. Ayrıca, HRMS sonuçları da sentezlenen bileşiklerin kimyasal yapılarını doğrulamaktadır.

\subsection{Sitotoksik Aktivite}

Sentezlenen üç bileşiğin sitotoksisiteleri, oral skuamoz kanser hücre hattına (HSC-2) ve insan normal oral hücrelerine (HGF ve HPLF) karşı in vitro olarak araştırılmıştır. Kanser tedavisinde klinikte kullanılan 
Doksorubisin (DXR) ve 5-florourasil (5-FU) referans ilaçlar olarak kullanılmışlardır.

Tablo 1. Bileşiklerin (1-3) insan OSCC hücre hattı ve normal oral hücrelere karşı sitotoksik aktivite sonuçları

\begin{tabular}{|c|c|c|c|c|c|c|c|c|c|}
\hline \multirow[b]{3}{*}{ Bileșik } & \multicolumn{7}{|c|}{$\mathrm{CC}_{50}(\mu \mathrm{M})$} & \multirow[b]{3}{*}{$\begin{array}{c}\mathrm{TS} \\
(\mathrm{B} / \mathrm{A})\end{array}$} & \multirow[b]{3}{*}{$\begin{array}{c}\text { PSE } \\
\left(\mathrm{B} / \mathrm{A}^{2}\right) \times 100\end{array}$} \\
\hline & \multicolumn{2}{|c|}{ OSCC } & \multicolumn{5}{|c|}{ İnsan normal oral hücreleri } & & \\
\hline & $\begin{array}{c}\text { HSC-2 } \\
\text { (A) }\end{array}$ & $\mathrm{SD}$ & HGF & SD & HPLF & SD & $\begin{array}{c}\text { ortalama } \\
\text { (B) }\end{array}$ & & \\
\hline 1 & 22.1 & 1.2 & 71.0 & 9.5 & 83.3 & 14.0 & 77.2 & 3.5 & 16 \\
\hline 2 & 63.7 & 3.1 & 54.7 & 23.3 & 81.0 & 3.0 & 67.8 & 1.1 & 2 \\
\hline 3 & 32.0 & 1.7 & 24.5 & 0.5 & 127.0 & 0.0 & 75.8 & 2.4 & 7 \\
\hline 5-FU* & 37.7 & 0.0 & $>1000$ & 0.0 & $>1000$ & 0.0 & $>1000$ & $>28.3$ & 80.7 \\
\hline $\mathrm{DXR} *$ & 0.5 & 0.1 & 0.7 & 0.0 & $>10$ & 0.0 & $>5.3$ & $>10.4$ & $>2030$ \\
\hline
\end{tabular}

* 5-Florourasil (5-FU) ve Doksorubisin (DXR) standart olarak kullanılmıştır.

Tablo 2. Bileşiklerin (1-3) asetilkolin esteraz (AChE) ve karbonik anhidraz enzimleri (hCA I ve II) inhibisyon sonuçları

\begin{tabular}{cccc}
\hline \multirow{2}{*}{ Bileşikler } & \multicolumn{3}{c}{$\operatorname{Ki}(\mu \mathrm{M})$} \\
\cline { 2 - 4 } & AChE & hCA I & hCA II \\
\hline $\mathbf{1}$ & $3.7 \pm 0.5$ & $70.6 \pm 6.7$ & $36.2 \pm 13.4$ \\
$\mathbf{2}$ & $4.8 \pm 0.3$ & $35.4 \pm 1.9$ & $38.8 \pm 8.8$ \\
$\mathbf{3}$ & $5.1 \pm 2.2$ & $44.1 \pm 2.3$ & $22.4 \pm 2.0$ \\
AZA* & - & $30.2 \pm 7.8$ & $4.4 \pm 0.6$ \\
TAC*** $^{*}$ & $7.9 \pm 2.0$ & - & - \\
\hline
\end{tabular}

\footnotetext{
*Asetazolamid (AZA) hCA I ve II izoenzimlerine karşı standart inhibitör olarak kullanılmıştır.

**Takrin (TAC) AChE enzimine karşı standart inhibitör olarak kullanılmıştır.
}

Bileşiklerin sitotoksik aktivite sonuçları Tablo 1'de gösterilmiştir. Sentezlenen bileşiklerin hepsi referans bileşik DXR'den $\left(\begin{array}{ll}0.5 \mu \mathrm{M}\end{array}\right)$ daha düşük sitotoksisiteye sahiptirler. Ancak, bileşik 1 ve 3 diğer referans bileşik 5-FU'dan daha yüksek sitotoksisiteye sahiptirler. Fenil türevi olan bileşik 1, sentezlenen bileşikler içerisinde HSC-2 hücre hattına karşı en yüksek sitotoksik aktiviteye $\left(\mathrm{CC}_{50}: 22.1 \mu \mathrm{M}\right)$ sahiptir. Bileşikler için dikkat edilmesi gereken önemli bir husus, tümör selektivitelerinin olup olmadıklarıdır. Canlı organizmada kanser hücreleri normal hücreler ile çevrelenmektedirler. Bu nedenle, bileşiklerin sitotoksik aktiviteleri HGF ve HPLF malign olmayan hücrelere karşı da değerlendirilmişlerdir. Bunun sonucunda bileşiklerin tümör selektivite değerleri (TS), bileşiklerin normal hücrelere karşı ortalama $\mathrm{CC}_{50}$ değerlerinin kanser hücre hatlarına karşı ortalama $\mathrm{CC}_{50}$ değerlerine bölünmesiyle hesaplanmıştır (Tablo 1). Tablodaki sonuçlara göre, bileşiklerin TS değerlerinin 1'den büyük olmaları bileşiklerin tümör-selektif olduklarını 
gösterse de, bileşiklerin, referans bileşikler DXR ve 5-FU'nun TS değerlerinden (sırasıyla 10.4 ve 28.3) daha düşük TS değerlerine sahip oldukları görülmektedir. Sentezlenen bileşikler içerisinde en yüksek TS değerine ise fenil türev olan bileşik 1 (3.5) sahiptir.

Lider bileşikler, tümörler için hem yüksek sitotoksik potansiyele hem de seçici sitotoksisiteye sahip olmalıdırlar. Hem yüksek potansiyel hem de seçici sitotoksisite açısından en çok umut vaat eden bileşikleri tanımlamak için, potansiyel seçicilik ifadesi (PSE) değerleri tanımlanmıştır (Dimmock et al., 1997). PSE değerleri şu eşitlikle hesaplanmaktadır: (Bileşiklerin TS değerleri/Bileşiklerin kanser hücre hatlarına karş1 CC50 değerleri) x 100 (Bilginer et al., 2019; Gul et al., 2009; Gul et al., 2018). Sentezlenen bileşiklerin PSE değerleri Tablo 1'de sunulmuştur. Tablodaki sonuçlardan görüldüğü üzere bileşiklerin hepsinin PSE değerleri referans bileşikler DXR (2030) ve 5-FU'dan (80.7) düşüktür. Sentezlenen bileşiklerden en yüksek PSE değerine sahip bileşik ise fenil türevi olan bileşik 1'dir (PSE: 16).

Tartışılması gereken diğer bir nokta, bileşiklerin aktiviteleri ile kimyasal yapıları arasında bir ilişki olup olmadığıdır. Tablo 1'de sunulan sonuçlara göre, molekülün aril kısmının fenil olduğu bileşik (1), aril kısmının furan (2) veya tiyofen (3) olan bileşiklerden daha yüksek sitotoksisite ve tümör seçiciliğine sahiptir. Başka bir deyişle, yapıdaki fenil halkasının tiyofen veya furan ile değiştirilmesi bileşiklerin sitotoksisitesi ve seçiciliğini azaltmıştır.

\subsection{Karbonik Anhidraz İnhbitör Aktivite}

Sentezlenen bileşiklerin hCA I ve hCA II izoenzimlere karşı inhibisyon potansiyelleri araştırılmış ve sonuçlar Tablo 2'de sunulmuştur. Referans ilaç olarak asetazolamid (AZA) kullanılmıştır. Sonuçlara bakıldığı zaman sentezlenen bileşiklerin hCA I ve hCA II enzim inhibisyon potansiyellerinin ifadesi olan $\mathrm{K}_{\mathrm{i}}$ değerlerinin, referans bileşikten (sırasıyla $30.2 \pm 7.8 \mu \mathrm{M}$ ve $4.4 \pm 0.6 \mu \mathrm{M}$ ) yüksek oldukları yani daha düşük inhibitör aktiviteye sahip oldukları görülmektedir. hCA I enzim inhibisyon sonuçlarına göre en yüksek inhibitör aktiviteye sahip bileşik furan türevi olan 2 numaralı bileşiktir $(35.4 \pm 1.9 \mu \mathrm{M})$ ve AZA ile yaklaşı aynı inhibisyon potansiyeline $(30.2 \pm 7.8 \mu \mathrm{M})$ sahiptir. En düşük hCA I inhibitör aktiviteye sahip bileşik ise fenil türevi olan bileşik 1'dir (70.6 16.7 $\mu \mathrm{M})$. hCA II enzim inhibisyon sonuçlarına göre ise en yüksek inhibitör aktiviteye sahip bileşik tiyofen türevi olan $\mathbf{3}$ numaralı bileşiktir $(22.4 \pm 2.0 \mu \mathrm{M})$.

\subsection{Asetilkolin Esteraz İnhibitör Aktivite}

Sentezlenen bileşiklerin asetilkolin esteraz (AChE) enzim inhibisyon potansiyelleri araştırılmış ve sonuçlar Tablo 2'de sunulmuştur. Referans bileşik olarak Takrin (TAC) kullanılmıştır. Tablodaki sonuçlara bakıldığı zaman sentezlenen bütün bileşiklerin $\mathrm{K}_{\mathrm{i}}$ değerlerinin referans bileşik TAC'den $(7.9 \pm 2.0 \mu \mathrm{M})$ düşük oldukları yani daha yüksek AChE inhibitör aktiviteye sahip oldukları görülmektedir. Sentezlenen bileşikler içerisinde en yüksek inhibitör aktiviteye sahip bileşik fenil türevi olan $\mathbf{1}$ numaralı bileşik $(3.7 \pm 0.5 \mu \mathrm{M})$ iken en düşük inhibitör aktiviteye sahip bileşik ise tiyofen türevi olan 3 numaralı bileşiktir $(5.1 \pm 2.2$ $\mu \mathrm{M})$. Sonuç olarak, yapıdaki fenil halkasının furan veya tiyofen ile değiştirilmesi $\mathrm{AChE}$ inhibitör aktiviteyi azaltmıştır. 


\section{Sonuç}

Genel kimyasal yapıs1 6-(3-Aril-2-propen-1oil)-2(3H)-benzoksazolon olan ve aril kısmı benzen, furan veya tiyofen olarak tasarlanan üç adet bileşik başarıyla sentezlenmiş ve yapılar1 ${ }^{1} \mathrm{H}$ NMR, ${ }^{13} \mathrm{C}$ NMR ve HRMS spektrumları ile aydınlatılmıştır. Bileşik 2, 6[3-(Furan-2-il)-2-propen-1-oil]-2(3H)benzoksazolon, sentezi ile ilk kez bu çalışmada rapor edilmiştir. Sentezlenen bileşiklerin sitotoksik aktiviteleri (bileşik 1 hariç), karbonik anhidraz inhibitör aktiviteleri (1-3) ve asetilkolin esteraz inhibitör aktiviteleri (1-3) ise ilk kez bu çalışma ile rapor edilmiştir. Bileşiklerin tümünün AChE enzim inhibitör aktiviteleri referans bileşikten yüksekken, sitotoksik ve hCA I/II inhibitör aktiviteleri referans bileşiklerden düşüktür. Yalnızca bileşik 2, referans bileşik AZA'ya benzer hCA I inhibisyon göstermiştir. Ayrıca, bileşiklerin aril kısmına fenil halkasının getirilmesinin, tiyofen veya furan halkasına göre, sitotoksik ve AChE enzim inhibitör aktiviteleri açısından daha faydalı bir modifikasyon olduğu bu çalışma ile ortaya konulmuştur. Ayrıca, sentezlenen bileşiklerin yüksek AChE inhibitör aktiviteleri nedeniyle ileriki çalışmalar için uygun öncü bileşikler oldukları görülmüştür.

\section{Teşekkür}

Çalışma sırasında, bileşiklerin sentezlenmesindeki katkılarından dolayı Prof. Dr. Halise İnci GÜL'e, NMR spektrumlarının yorumlanmasındaki katkılarından dolayı Prof. Dr. Cavit KAZAZ'a, sentezlenen bileşiklerin karbonik anhidraz ve asetilkolin esteraz inhibisyon aktivite çalışmalarındaki katkılarından dolayı Prof. Dr. İlhami GÜLÇİN'e, sitotoksik aktivite çalışmalarındaki katkılarından dolayı
Prof. Dr. Hiroshi Sakagami’ye ve çalışmayı destekleyen Atatürk Üniversitesi Araştırma Fon Saymanlığı'na (BAP Proje No: 2016/118) teşekkürlerimi sunarım.

\section{Kaynaklar}

Abonia, R., Insuasty, D., Castillo, J., Insuasty, B., Quiroga, J., Nogueras, M., and Cobo, J. (2012). Synthesis of novel quinoline-2-one based chalcones of potential anti-tumor activity. European journal of medicinal chemistry, 57, 29-40.

Alterio, V., Di Fiore, A., D’Ambrosio, K., Supuran, C. T., and De Simone, G. (2012). Multiple binding modes of inhibitors to carbonic anhydrases: how to design specific drugs targeting 15 different isoforms? Chemical reviews, 112(8), 4421-4468.

Anand, P., and Singh, B. (2013). A review on cholinesterase inhibitors for Alzheimer's disease. Archives of pharmacal research, 36(4), 375-399.

Baviskar, B.A., Baviskar, B., Shiradkar, M., Deokate, U., and Khadabadi, S. (2009). Synthesis and Antimicrobial Activity of SomeNovel Benzimidazolyl Chalcones. Journal of Chemistry, 6(1), 196-200.

Bilginer, S., Gul, H.I., Erdal, F.S., Sakagami, H., Levent, S., Gulcin, I., and Supuran, C. T. (2019). Synthesis, cytotoxicities, and carbonic anhydrase inhibition potential of 6(3-aryl-2-propenoyl)-2 (3H)-benzoxazolones. Journal of enzyme inhibition and medicinal chemistry, 34(1), 1722-1729.

Bilginer, S., Gul, H.I., Mete, E., Das, U., Sakagami, H., Umemura, N., and Dimmock, J.R. (2013). 1-(3-Aminomethyl-4hydroxyphenyl)-3-pyridinyl-2-propen-1ones: a novel group of tumour-selective 
cytotoxins. Journal of enzyme inhibition and medicinal chemistry, 28(5), 974-980.

Bilginer, S., Unluer, E., Gul, H. I., Mete, E., Isik, S., Vullo, D., and Supuran, C. T. (2014). Carbonic anhydrase inhibitors. Phenols incorporating 2-or 3-pyridyl-ethenylcarbonyl and tertiary amine moieties strongly inhibit Saccharomyces cerevisiae $\beta$-carbonic anhydrase. Journal of enzyme inhibition and medicinal chemistry, 29(4), 495-499.

Bonte, J. P., Lesieur, D., Lespagnol, C., Cazın, J. C., and Cazin, M. (1975). 6-AcylBenzoxazolinone 2. Mitt. Synthese Einiger Ihrer Umwandlungsprodukte. Chemischer Informationsdienst, 6(10).

Cacabelos, R. (2008). Pharmacogenomics in Alzheimer's disease. In Pharmacogenomics in Drug Discovery and Development (pp. 213-357): Springer.

Chen, M., Christensen, S. B., Blom, J., Lemmich, E., Nadelmann, L., Fich, K., and Kharazmi, A. (1993). Licochalcone A, a novel antiparasitic agent with potent activity against human pathogenic protozoan species of Leishmania. Antimicrobial agents and chemotherapy, 37(12), 2550-2556.

Chen, M., Christensen, S. B., Zhai, L., Rasmussen, M., Theander, T., Frøkjaer, S., and Kharazmi, A. (1997). The novel oxygenated chalcone, 2, 4-dimethoxy-4'butoxychalcone, exhibits potent activity against human malaria parasite Plasmodium falciparum in vitro and rodent parasites Plasmodium berghei and Plasmodium yoelii in vivo. Journal of Infectious Diseases, 176(5), 1327-1333.

Cunha, G. M. d. A., Fontenele, J. B., Nobre Júnior, H. V., de Sousa, F. C., Silveira, E. R., Nogueira, N. A., and Costa-Lotufo, L. V.
(2003). Cytotoxic activity of chalcones isolated from Lonchocarpus sericeus (Pocr.) Kunth. Phytotherapy Research: An International Journal Devoted to Pharmacological and Toxicological Evaluation of Natural Product Derivatives, 17(2), 155-159.

De, R. V., Scambia, G., Benedetti, P. P., Ranelletti, F., Bonanno, G., Ercoli, A., and Mancuso, S. (1995). Effect of synthetic and naturally occurring chalcones on ovarian cancer cell growth: structure-activity relationships. Anti-cancer drug design, 10(6), 481-490.

Di Resta, C., and Ferrari, M. (2019). New molecular approaches to Alzheimer's disease. Clinical biochemistry.

Dimmock, J., Kumar, P., Allen, T., Kao, G., Halleran, S., and Balzarini, J. (1997). Synthesis and cytotoxic evaluation of some carbohydrazones and thiocarbohydrazones of various unsaturated ketones and related Mannich bases. Die Pharmazie, 52(3), 182186.

El-Hady, H. A., and Abubshait, S. A. (2015). Synthesis of imidazolinone and benzoxazole derivatives, and evaluation of their anticancer activity. Research on chemical intermediates, 41(3), 1833-1841.

Erciyas, E., Erkaleli, H., and Cosar, G. (1994). Antimicrobial evaluation of some styryl ketone derivatives and related thiol adducts. Journal of pharmaceutical sciences, 83(4), 545-548.

Ferlay, J., Colombet, M., Soerjomataram, I., Mathers, C., Parkin, D., Piñeros, M., and Bray, F. (2019). Estimating the global cancer incidence and mortality in 2018: GLOBOCAN sources and methods. 
International journal of cancer, 144(8), 1941-1953.

Gul, H. I., Cizmecioglu, M., Zencir, S., Gul, M., Canturk, P., Atalay, M., and Topcu, Z. (2009). Cytotoxic activity of 4'hydroxychalcone derivatives against Jurkat cells and their effects on mammalian DNA topoisomerase I. Journal of enzyme inhibition and medicinal chemistry, 24(3), 804-807.

Gul, H. I., Mete, E., Eren, S. E., Sakagami, H., Yamali, C., and Supuran, C. T. (2017). Designing, synthesis and bioactivities of 4[3-(4-hydroxyphenyl)-5-aryl-4, 5-dihydropyrazol-1-yl] benzenesulfonamides. Journal of enzyme inhibition and medicinal chemistry, 32(1), 169-175.

Gul, H. I., Mete, E., Taslimi, P., Gulcin, I., and Supuran, C. T. (2017). Synthesis, carbonic anhydrase I and II inhibition studies of the 1, 3, 5-trisubstituted-pyrazolines. Journal of enzyme inhibition and medicinal chemistry, 32(1), 189-192.

Gul, H. I., Yamali, C., Bulbuller, M., Kirmizibayrak, P. B., Gul, M., Angeli, A., and Supuran, C. T. (2018). Anticancer effects of new dibenzenesulfonamides by inducing apoptosis and autophagy pathways and their carbonic anhydrase inhibitory effects on hCA I, hCA II, hCA IX, hCA XII isoenzymes. Bioorganic chemistry, 78, 290-297.

Gul, H. I., Yamali, C., Gunesacar, G., Sakagami, H., Okudaira, N., Uesawa, Y., and Kagaya, H. (2018). Cytotoxicity, apoptosis, and QSAR studies of phenothiazine derived methoxylated chalcones as anticancer drug candidates. Medicinal Chemistry Research, 27(10), 2366-2378.

Gul, H. I., Yamali, C., Yesilyurt, F., Sakagami, H., Kucukoglu, K., Gulcin, I., and
Supuran, C. T. (2017). Microwave-assisted synthesis and bioevaluation of new sulfonamides. Journal of enzyme inhibition and medicinal chemistry, 32(1), 369-374.

Gul, H.I., Demirtas, A., Ucar, G., Taslimi, P., and Gulcin, I. (2017). Synthesis of Mannich bases by two different methods and evaluation of their acetylcholine esterase and carbonic anhydrase inhibitory activities. Letters in drug design \& discovery, 14(5), 573-580.

Gulcan, H. O., Kupeli, E., Unlu, S., Yesilada, E., and Sahin, M. F. (2003). 4-(5-Chloro-2 (3H)-benzoxazolon-3-yl) Butanoic Acid Derivatives: Synthesis, Antinociceptive and Anti-inflammatory Properties. Archiv der Pharmazie: An International Journal Pharmaceutical and Medicinal Chemistry, 336(10), 477-482.

Hasan, A., Khan, K. M., Sher, M., Maharvi, G. M., Nawaz, S. A., Choudhary, M.,and Supuran, C. T. (2005). Synthesis and inhibitory potential towards acetylcholinesterase, butyrylcholinesterase and lipoxygenase of some variably substituted chalcones. Journal of enzyme inhibition and medicinal chemistry, 20(1), 41-47.

Ivanova, Y., Momekov, G., \& Petrov, O. (2009). Synthesis of novel substituted 1, 3diarylpropenone derivatives and their in vitro cytotoxic activity. Letters in Drug Design \& Discovery, 6(5), 353-357.

Ivanova, Y., Momekov, G., Petrov, O., Karaivanova, M., and Kalcheva, V. (2007). Cytotoxic Mannich bases of 6-(3-aryl-2propenoyl)-2(3H)-benzoxazolones. European journal of medicinal chemistry, 42(11-12), 1382-1387. 
Ivanova, Y. B., Momekov, G. T., and Petrov, O. I. (2013). New heterocyclic chalcones. Part 6. Synthesis and cytotoxic activities of 5-or 6-(3-aryl-2-propenoyl)-2 (3H)benzoxazolones. Heterocyclic Communications, 19(1), 23-28.

Kandepu, N. M. (2002). Mannich bases of chalcones and cyclohexanones as candidate cytotoxic agents.

Kazaz C., Bilginer S., Engin F.S., Gül H.I. (2017). Synthesis of New 2(3H)Benzoxazolone,6-[1-oxo-3-(2- furanyl)-2propenyl] and Spectral Investigation With Advanced NMR Techniques and The NMR Shift Reagent [Eu(fod)3] Paper presented at the TRAMECH IX, Fez, Morocco, 260.

Koca, M., Yerdelen, K. O., Anil, B., Kasap, Z., Sevindik, H., Ozyurek, I., and Turkaydin, K. (2016). Design, synthesis and biological activity of $1 \mathrm{H}$-indene-2-carboxamides as multi-targeted anti-Alzheimer agents. Journal of enzyme inhibition and medicinal chemistry, 31(sup2), 13-23.

Köksal, M., Gökhan, N., Erdoğan, H., Özalp, M., and Ekizoğlu, M. (2002). Synthesis of 3(4-substituted benzoxazolinones and screening antimicrobial activities. Il Farmaco, 57(7), 535-538.

Lahtchev, K., Batovska, D., St P, P., Ubiyvovk, V., and Sibirny, A. (2008). Antifungal activity of chalcones: A mechanistic study using various yeast strains. European journal of medicinal chemistry, 43(10), 2220-2228.

Langella, E., Alterio, V., D’Ambrosio, K., Cadoni, R., Winum, J.-Y., Supuran, C. T., and Di Fiore, A. (2019). Exploring benzoxaborole derivatives as carbonic anhydrase inhibitors: a structural and computational analysis reveals their conformational variability as a tool to increase enzyme selectivity. Journal of enzyme inhibition and medicinal chemistry, 34(1), 1498-1505.

Lespagnol, A., Mercier, J., Sestier, R., and Marinacce, P. (1952). * Etude De La Benzoxazolone Et De Certains De Ses Derives. Bulletın De La Societe De Chımı Bıologıque, 34(5-6), 597-605.

Liu, H.-r., Liu, X.-j., Fan, H.-q., Tang, J.-j., Gao, X.-h., and Liu, W.-K. (2014). Design, synthesis and pharmacological evaluation of chalcone derivatives as acetylcholinesterase inhibitors. Bioorganic \& medicinal chemistry, 22(21), 6124-6133.

Loveman, E., Green, C., Kirby, J., Takeda, A., Picot, J., Payne, E., and Clegg, A. (2006). The clinical and cost-effectiveness of donepezil, rivastigmine, galantamine and memantine for Alzheimer's disease. In NIHR Health Technology Assessment programme: Executive Summaries: NIHR Journals Library.

Miranda, C. L., Stevens, J. F., Ivanov, V., McCall, M., Frei, B., Deinzer, M. L., and Buhler, D. R. (2000). Antioxidant and prooxidant actions of prenylated and nonprenylated chalcones and flavanones in vitro. Journal of agricultural and food chemistry, 48(9), 3876-3884.

Mulazim, Y., Berber, C., Erdogan, H., Ozkan, M. H., and Kesanli, B. (2017). Synthesis and analgesic activities of some new 5-chloro-2(3H)-benzoxazolone derivatives. The EuroBiotech Journal, 1(3), 235-240. 
Murty, M., Ram, K. R., Rao, R. V., Yadav, J., Rao, J. V., Cheriyan, V. T., and Anto, R. J. (2011). Synthesis and preliminary evaluation of 2-substituted-1, 3-benzoxazole and 3-[(3-substituted) propyl]-1, 3benzoxazol-2 $(3 \mathrm{H})$-one derivatives as potent anticancer agents. Medicinal Chemistry Research, 20(5), 576-586.

Nowakowska, Z. (2007). A review of antiinfective and anti-inflammatory chalcones. European journal of medicinal chemistry, 42(2), 125-137.

Palaska, E. (2004). Antkanser İlaçlar. In Farmasötik Kimya: Hacettepe Üniversitesi Yayınları.

Rivas-Vazquez, R. A. (2001). Cholinesterase inhibitors: Current pharmacological treatments for Alzheimer's disease. Professional Psychology: Research and Practice, 32(4), 433.

Rocha, L., Almeida, J., Macedo, R., \& Barbosa-Filho, J. (2005). A review of natural products with antileishmanial activity. Phytomedicine, 12(6-7), 514-535.

Supuran, C. T. (2008). Carbonic anhydrasesan overview. Current pharmaceutical design, 14(7), 603-614.

Supuran, C.T. (2017). Advances in structurebased drug discovery of carbonic anhydrase inhibitors. Expert opinion on drug discovery, 12(1), 61-88.

Supuran, C.T. (2018). Carbon-versus sulphur-based zinc binding groups for carbonic anhydrase inhibitors? Journal of enzyme inhibition and medicinal chemistry, 33(1), 485-495.

Supuran, C. T., and Scozzafava, A. (2007). Carbonic anhydrases as targets for medicinal chemistry. Bioorganic \& medicinal chemistry, 15(13), 4336-4350.

Thacker, P.S., Shaikh, P., Angeli, A., Arifuddin, M., and Supuran, C. T. (2019). Synthesis and biological evaluation of novel 8 -substituted quinoline-2-carboxamides as carbonic anhydrase inhibitors. Journal of enzyme inhibition and medicinal chemistry, 34(1), 1172-1177.

Toru, O., Yoshihito, O., and Shaji, S. (2000). Jpn. Kokai Tokkyo Koho JP 11, 349, 521. Paper presented at the Chem. Abstr.

Vigroux, A., and Bergon, M. (1995). Synthesis of prodrugs and a mutual prodrug of chlorzoxazone and acetaminophen based on a masked benzoxazolone. Bioorganic \& medicinal chemistry letters, 5(5), 427-430.

Wang, H., and Ng, T. (2002). Demonstration of antifungal and anti-human immunodeficiency virus reverse transcriptase activities of 6-methoxy-2-benzoxazolinone and antibacterial activity of the pineal indole 5-methoxyindole-3-acetic acid. Comparative Biochemistry and Physiology Part C: Toxicology \& Pharmacology, 132(2), 261268.

Yamali, C., Gul, H. I., Ece, A., Taslimi, P., and Gulcin, I. (2018). Synthesis, molecular modeling, and biological evaluation of 4-[5aryl-3-(thiophen-2-yl)-4, 5-dihydro-1Hpyrazol-1-yl] benzenesulfonamides toward acetylcholinesterase, carbonic anhydrase I and II enzymes. Chemical biology \& drug design, 91(4), 854-866.

Yamali, C., Gul, H. I., Sakagami, H., and Supuran, C. T. (2016). Synthesis and bioactivities of halogen bearing phenolic chalcones and their corresponding bis 
Mannich bases. Journal of enzyme inhibition and medicinal chemistry, 31(sup4), 125-131.

Yamali, C., Tugrak, M., Gul, H. I., Tanc, M., and Supuran, C. T. (2016). The inhibitory effects of phenolic Mannich bases on carbonic anhydrase I and II isoenzymes. Journal of enzyme inhibition and medicinal chemistry, 31(6), 1678-1681.

Yerdelen, K.O. and Gul, H.I. (2013). Synthesis and anticholinesterase activity of fumaramide derivatives. Medicinal Chemistry Research, 22(10), 4920-4929.

Zhang, P., Xu, S., Zhu, Z., and Xu, J. (2019). Multi-target design strategies for the improved treatment of Alzheimer's disease. European journal of medicinal chemistry, 176. 228-247.

Zvěřová, M. (2019). Clinical aspects of Alzheimer's disease. Clinical biochemistry, 72, 3-6. 